\title{
HIGH-RESOLUTION TOPOGRAPHY OF MERCURY FROM MESSENGER ORBITAL STEREO IMAGING - THE SOUTHERN HEMISPHERE QUADRANGLES
}

\author{
F. Preusker ${ }^{1}$, J. Oberst ${ }^{1,2}$, A. Stark ${ }^{1}$, S. Burmeister ${ }^{2}$ \\ ${ }^{1}$ German Aerospace Center (DLR), Institute of Planet. Research, Berlin, Germany - \\ (stephan.elgner, frank.preusker, alexander.stark, juergen.oberst)@dlr.de \\ ${ }^{2}$ Technical University Berlin, Institute for Geodesy and Geoinformation Sciences, Berlin, Germany - \\ (steffi.burmeister, juergen.oberst)@tu-berlin.de
}

Commission VI, WG VI/4

KEY WORDS: Mercury, MESSENGER, Digital Terrain Models

\section{ABSTRACT:}

We produce high-resolution (222 m/grid element) Digital Terrain Models (DTMs) for Mercury using stereo images from the MESSENGER orbital mission. We have developed a scheme to process large numbers, typically more than 6000, images by photogrammetric techniques, which include, multiple image matching, pyramid strategy, and bundle block adjustments. In this paper, we present models for map quadrangles of the southern hemisphere H11, H12, H13, and H14.

\section{INTRODUCTION}

The MErcury Surface, Space ENviorment, GEochemistry, and Ranging (MESSENGER) spacecraft entered orbit about Mercury in March 2011 to carry out a comprehensive topographic mapping of the planet. Topographic measurement techniques include laser altimetry (Zuber et al., 2012), limb profiling (Elgner et al., 2014), radio occultation (Perry et al., 2015), and stereo imaging (Oberst et al., 2010; Preusker et al., 2011; Preusker et al., 2017). We are concerned with the production of a high-resolution digital terrain models (DTM) using stereo photogrammetry.

While we previously reported on the equatorial quadrangles $\mathrm{H} 6$ "Kuiper" and H7 "Beethoven" and high-latitude northern quadrangle H3 "Shakespeare" and H5 "Hokusai", we are focused on topographic models of the southern hemisphere. The southern quadrangles differ from the equatorial and northern quadrangles as the spacecraft, moving in a highly elliptic orbit, was at high altitudes when moving above the southern surface. Consequently, the spacecraft took almost exclusively images by the Narrow-Angle Camera (NAC). Also, in the southern hemisphere, no MLA (Mercury Laser Altimeter) data are available, thus preventing the cross-validation of the photogrammetrically derived data products with Laser altimetry.

\section{MESSENGER MISSION AND CAMERA}

MESSENGER was equipped with the Mercury Dual Imaging System (MDIS), which consisted of two framing cameras, a wide-angle camera (WAC) and a narrow-angle camera (NAC), co-aligned on a pivot platform and equipped with identical 1024x1024-pixel charge-coupled device (CCD) sensors (Hawkins et al., 2007). Contrary to the WAC (which features 11 narrowband color- and one broadband clear filter) the NAC is equipped with a broadband clear filter only. Both cameras consist of a compact off-axis optical system that has been geometrically calibrated using laboratory as well as in-flight data (Hawkins et al., 2007). The harsh thermal environment of
Mercury requires sophisticated models for calibrations of focal length and distortion of the camera. In particular, the WAC camera and NAC camera were demonstrated to show a linear increase in focal length by up to $0.10 \%$ over the typical range of temperatures $\left(-20\right.$ to $\left.+20{ }^{\circ} \mathrm{C}\right)$ during operation, which causes a maximum displacement of up to 1 pixel. Following methods described earlier (Oberst et al., 2011) the focal length dependencies and geometric distortions for WAC and NAC were modeled using observations of star fields in different temperature regimes of the MESSENGER orbit (Denevi et al., 2017). We use recently updated data on the focal-length behavior of the camera, due to thermal effects (see companion paper at this conference by Burmeister et al., 2018).

\section{PHOTOGRAMMETRIC PROCESSING}

The construction of the DTMs follows procedures we have previously used for Mercury (Oberst et al., 2010; Preusker et al., 2011; Preusker et al., 2017). The photogrammetric processing comprises five main tasks, which are described in the following sections.

\subsection{Image selection}

In order to manage the complexity and challenges of the global surface reconstruction, we chose to derive individual digital terrain models following a scheme of 15 quadrangles (Figure 1) proposed for Mercury (Greeley and Batson, 1990). Using image footprint information, we identify all narrow-angle and wideangle filter $\mathrm{G}$ images that had a resolution between $50 \mathrm{~m}$ to 350 $\mathrm{m}$ and that fall into the area of a quadrangle. The stereophotogrammetric analyses require a favorable image- and illumination geometry, which affect quantity and quality of matched tie points and resulting DTM points. As image coverage, image scale and illumination conditions vary substantially during the MESSENGER mapping mission, the "quality" of stereo conditions vary accordingly.

* Corresponding author 
To identify stereo combinations we formed a latitude/longitude grid of $0.1^{\circ} \times 0.1^{\circ}$, in which we identified the images covering each grid element (typically: 3 - 300 images), for which we computed the relevant stereo and illumination angles (i.e., sun incidence, emission, and sun phase angles for each pair). Only those pairs were considered that had image scales differing by not more than a factor of three. All pairs were tested against the conditions of Table 1 . We aim at the identification of "combinations" of images concatenated by favorable stereo conditions. Typically, we find combinations with five to eight members; combinations with less than three images were discarded from the subsequent analysis.

\begin{tabular}{|c|l|l|l|}
\hline Parameter & Optimal & Adequate & Minimal \\
\hline Illumination & $0^{\circ}-10^{\circ}$ & $0^{\circ}-10^{\circ}$ & $0^{\circ}-10^{\circ}$ \\
variation & & & \\
Stereo angle & $15^{\circ}, 15^{\circ}-65^{\circ}$ & $5^{\circ}, 15^{\circ}-65^{\circ}$ & $5^{\circ}, 12^{\circ}-65^{\circ}$ \\
Incidence angle & $5^{\circ}-55^{\circ}$ & $5^{\circ}-80^{\circ}$ & $5^{\circ}-90^{\circ}$ \\
Emission angle & $0^{\circ}-55^{\circ}$ & $0^{\circ}-65^{\circ}$ & $0^{\circ}-70^{\circ}$ \\
Sun phase angle & $5^{\circ}-135^{\circ}$ & $5^{\circ}-145^{\circ}$ & $5^{\circ}-160^{\circ}$ \\
\hline
\end{tabular}

Table 1: Optimal, adequate and minimal parameter ranges for key stereo observing attributes.

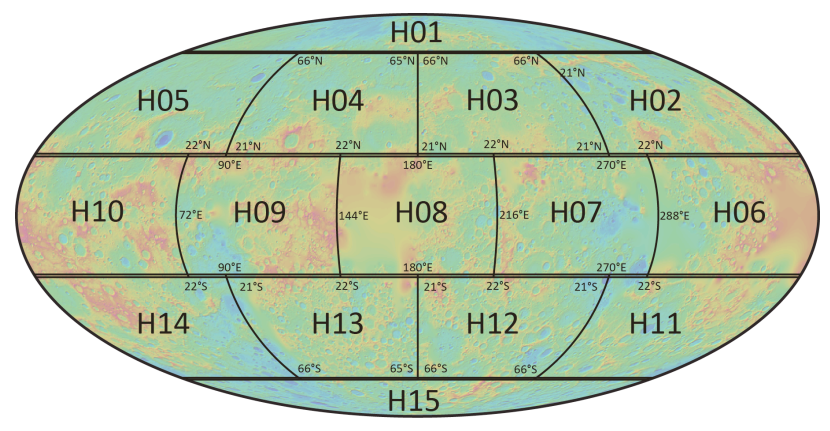

Figure 1: Mercury's 15 tiles quadrangle scheme.

\subsection{Multi-image Matching}

Images are initially rectified to a common map projection, i.e., to one common scale, using nominal orbit and pointing information, Mercury's mean radius and a priori knowledge of the topography as reference. The processing is carried out in several stages following a pyramid strategy, where map scale and a priori topography are selected for each pyramid level separately. A multi-image matching technique (Wewel, 1996) is applied in order to derive conjugate points in each of the stereo combinations. The algorithm makes use of area-based correlation to derive approximate values for the image coordinates, which are refined to sub-pixel accuracy by leastsquares matching. The correlation is done for each master image as the reference image with all stereo partners, i.e. all overlapping images. After the matching, the derived image coordinates are transformed back to raw data geometry (Scholten et al., 2005). For each stereo combination two kinds of tie-point data sets are generated. First, the images are matched in a sparse grid usually about every 20th pixel (used as input for the bundle adjustment), whereas in a second run a pixel-by-pixel grid is produced (used for DTM generation).

\subsection{Bundle Block Adjustment}

We carry out a least-squares inversion of image tie-point measurements to determine the unknown six camera orientation parameters (three metric parameters for the camera position and three angular parameters for the camera pointing) as well as three coordinates for each tie-point in object space. The relation between tie-point coordinates and the corresponding surface point is mathematically defined through the so-called collinearity equations (Albertz and Wiggenhagen, 2009). Nominal navigation is used to begin the iterations.

\subsection{Object Point Calculation}

Next, we compute the line of sight for each observation, defined by the image coordinates, the geometric calibration, and the orientation data. Lines of sight for tie-points are combined to compute forward ray intersections using least-squares techniques. The redundancy given by multi-stereo capability allows us to accept only those object points that are defined by at least three stereo observations. Thus, we avoid occasional gross matching errors, typical for simple two-image matching. We obtain object points in Cartesian coordinates and their relative accuracies.

\subsection{DTM Interpolation}

To form the DTM we combine the object points of all models. First, all points are transformed from Cartesian to spherical coordinates (latitude/longitude/radius), where height values are computed with respect to Mercury's adopted mean radius of $2439.4 \mathrm{~km}$. The latitude/longitude coordinates are transformed to the standard map projection of our quadrangle. The gridded DTM is formed by interpolation, using a distance-weighted mean filtering technique (Gwinner et al., 2009) and a gap-filling algorithm using data from preceding DTM pyramid levels of reduced resolution.

\section{RESULTS}

All southern quadrangles are covered almost exclusively by NAC images, with resolutions ranging from $50 \mathrm{~m} /$ pixel to 350 $\mathrm{m} / \mathrm{pixel}$. The four DTMs are produced in Lambert Conformal projection with the first standard parallel at $30^{\circ} \mathrm{S}$ and second standard parallel at $58^{\circ} \mathrm{S}$. The grid spacing is 192 pixel per degree ( $222 \mathrm{~m} /$ pixel).

\subsection{H11 Quadrangle "Discovery"}

The $\mathrm{H} 11$ quadrangle extends from $270.0^{\circ} \mathrm{E}$ to $360.0^{\circ} \mathrm{E}$ longitude respectively. Thus, it is connected northward to the equatorial quadrangles $\mathrm{H} 6$ and $\mathrm{H} 07$ (see Figure 1). In total we have selected about 9400 NAC images. We identified about 29,700 independent stereo combinations which yield a connected block consisting of about 6000 MDIS NAC images. For the bundle block adjustment 90,000 tie point observation were used, which improves the $3 \mathrm{D}$ point accuracy from $\pm 1020 \mathrm{~m}$ to $\pm 50 \mathrm{~m}$. From dense image matching we derived about 7.9 billion surface points with a mean accuracy of about $\pm 40 \mathrm{~m}$. The gridded DTM is centered at $315^{\circ} \mathrm{E}$ degree longitude (see figure 2). The vertical accuracy of the H11 DTM is about $35 \mathrm{~m}$. The H11 DTM comprises a total height range of $9.6 \mathrm{~km}$. This model includes the large impact basins Aneirin $(480 \mathrm{~km}$ diameter $)$ and Haydn ( $\sim 250 \mathrm{~km}$ diameter) (see Figure 2). It also contains the prominent lobate scarp "Discovery Rupes", about $400 \mathrm{~km}$ long. 


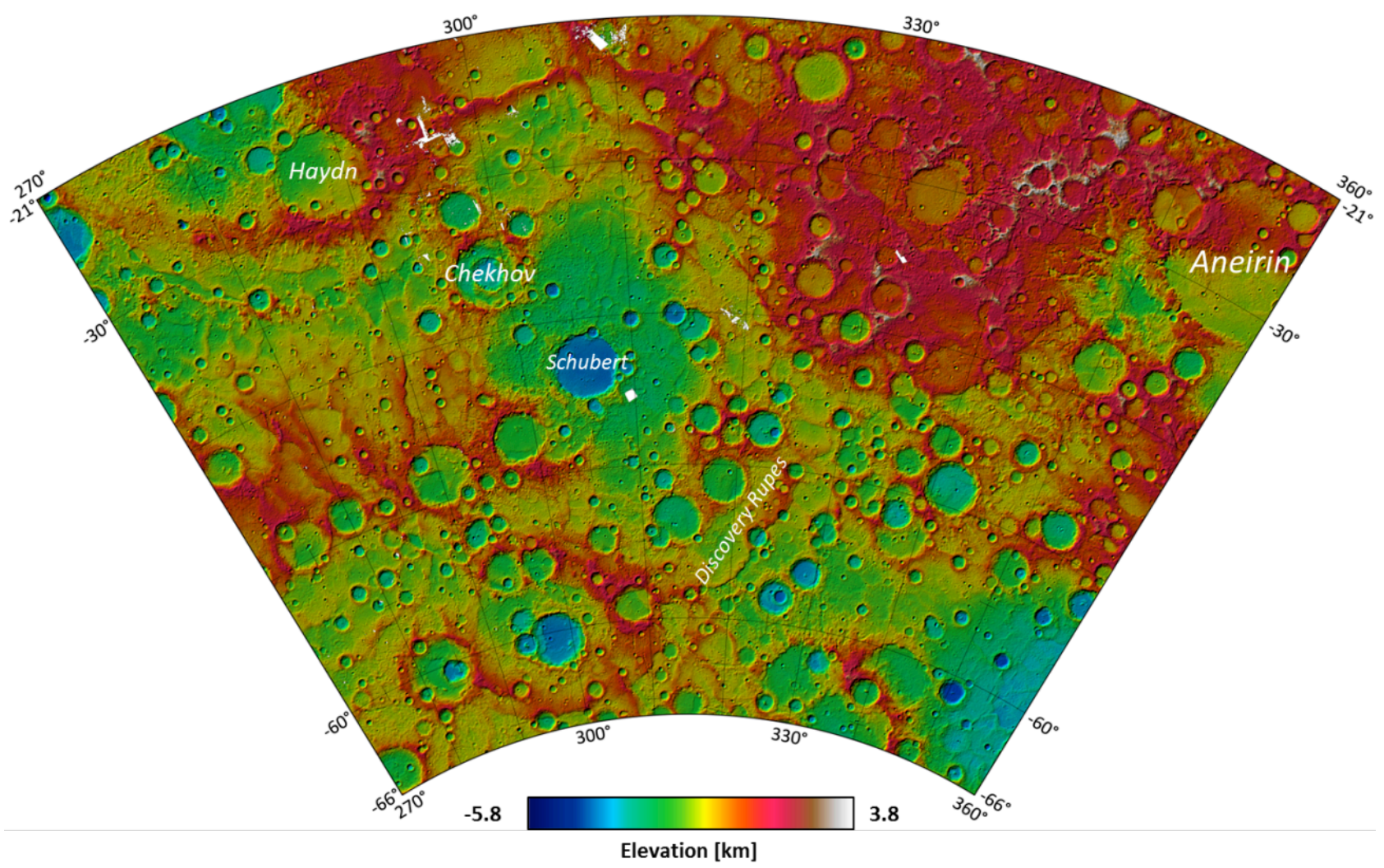

Figure 2: H11 "Discovery" quadrangle DTM.

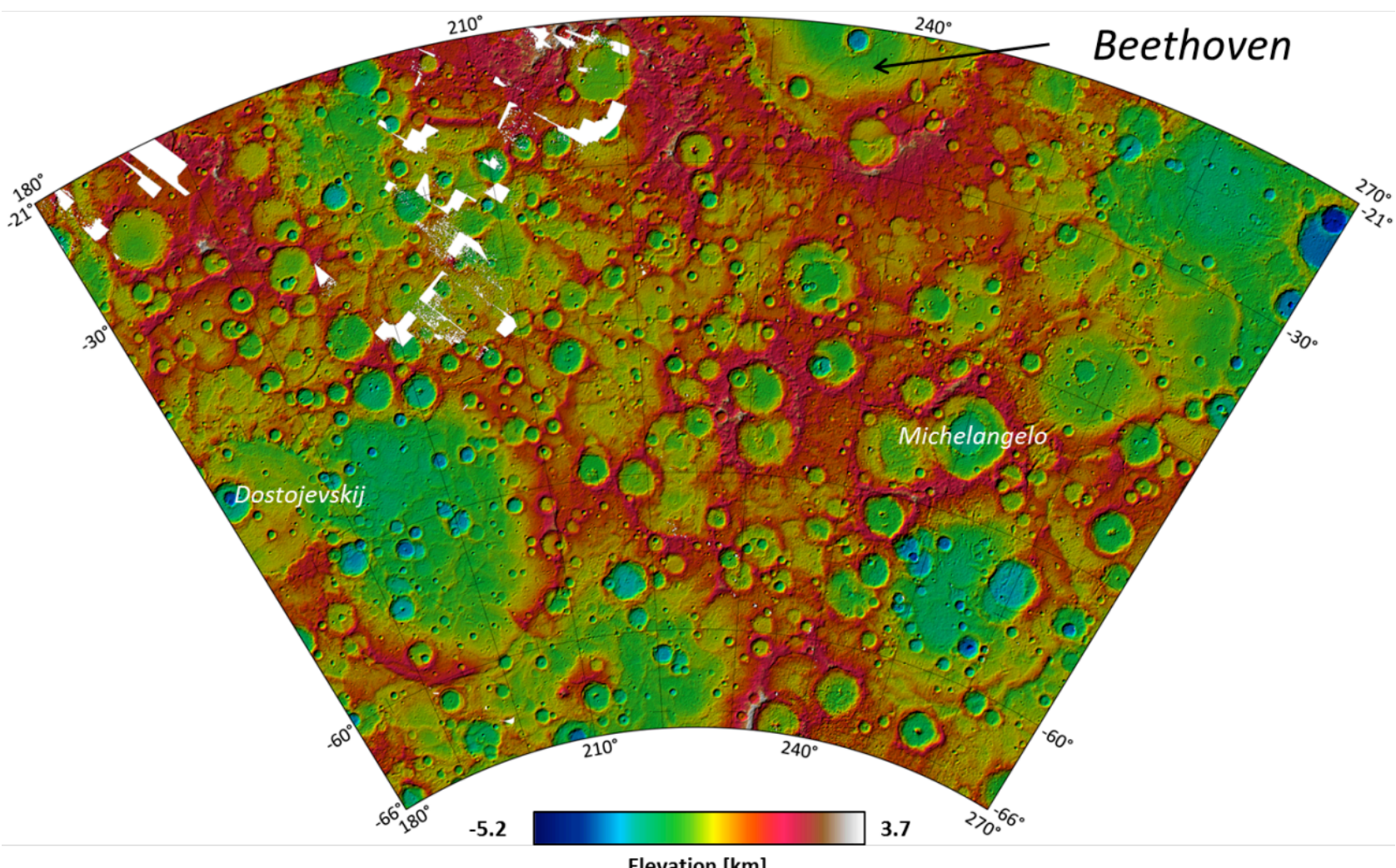

Figure 3: H12 "Michelangelo" quadrangle DTM. 


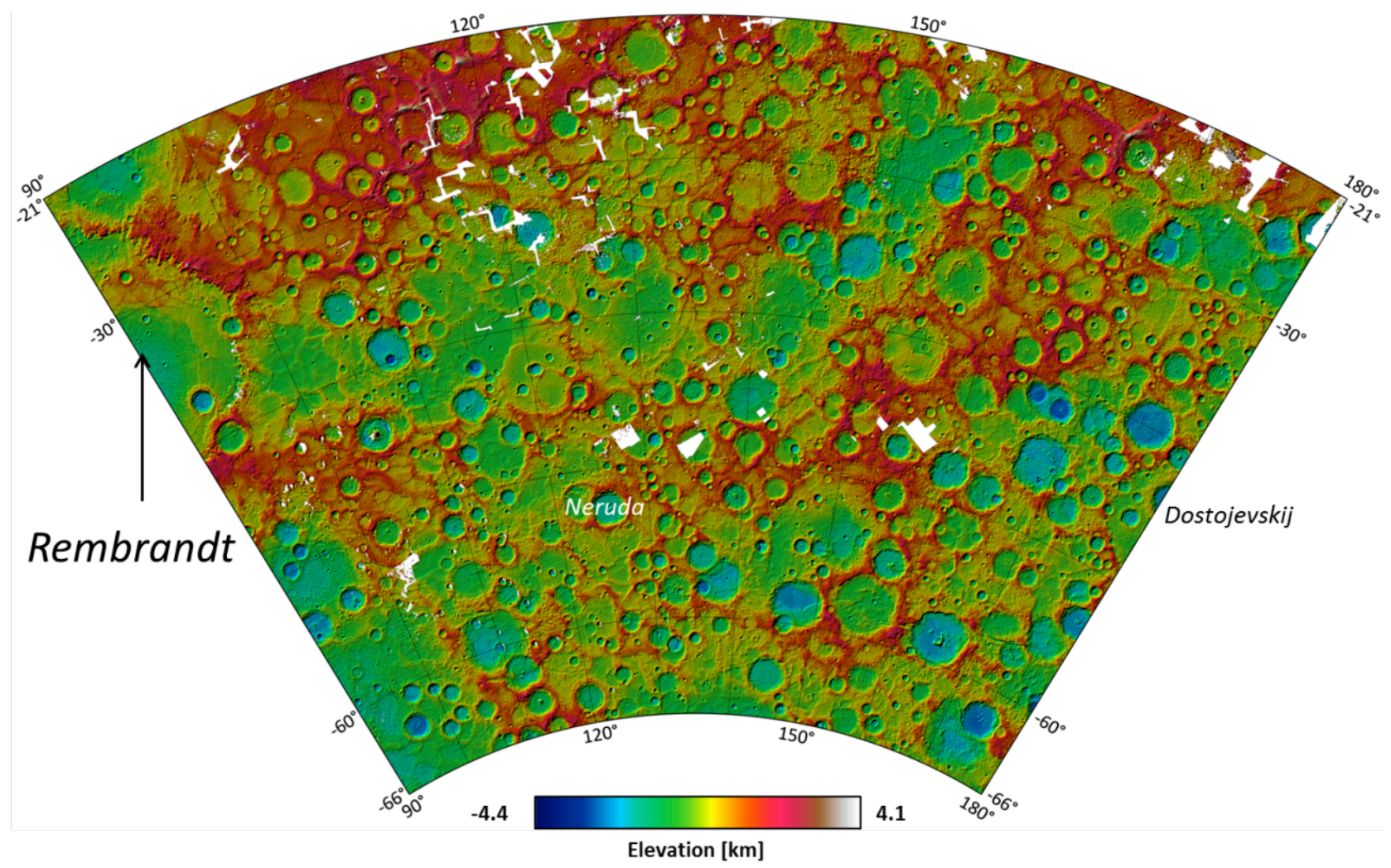

Figure 4: H13 "Neruda" quadrangle DTM.

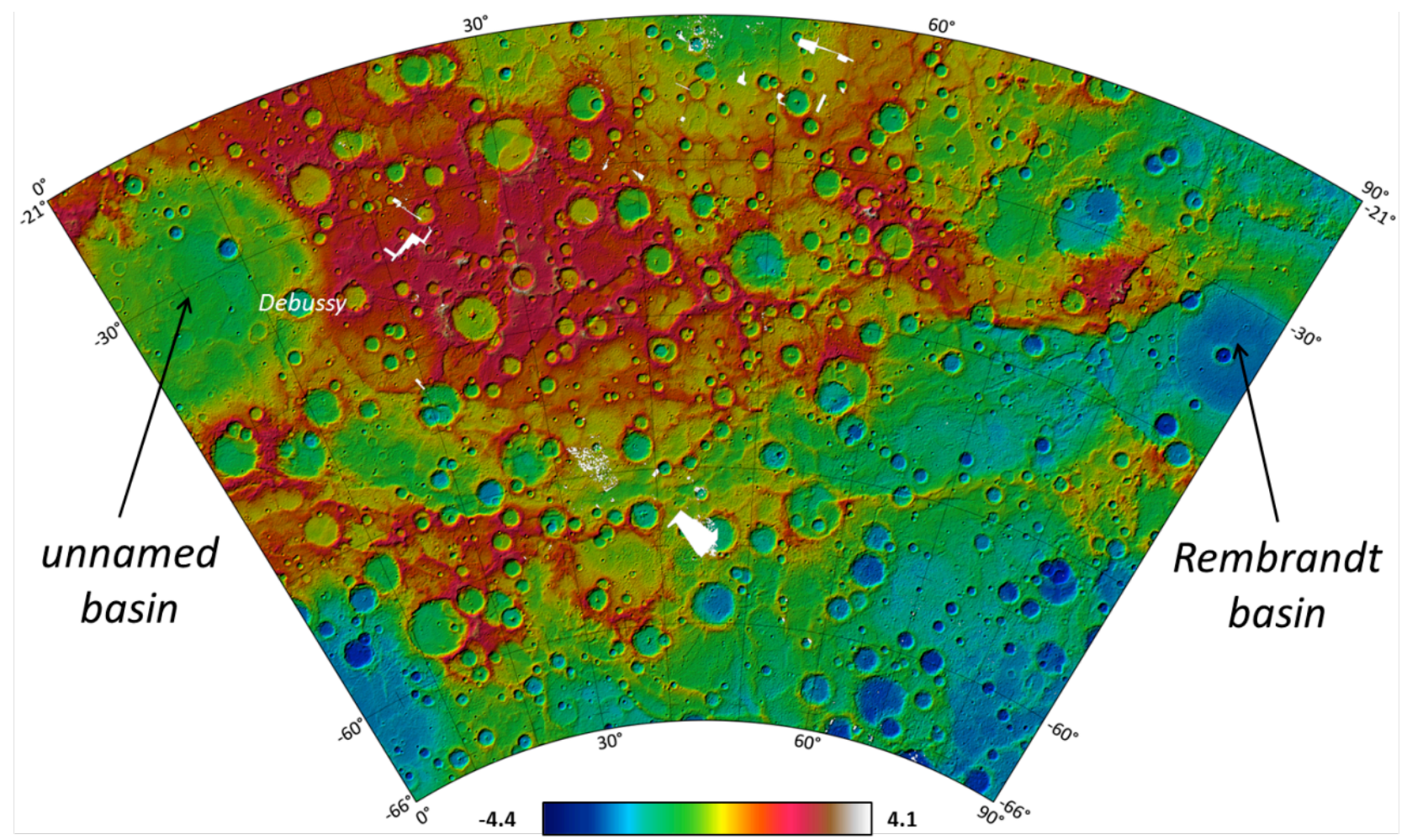

Elevation $[\mathrm{km}]$

Figure 5: H14 "Debussy” quadrangle DTM. 


\subsection{H12 Quadrangle "Michelangelo"}

The $\mathrm{H} 12$ quadrangle extends from $180.0^{\circ} \mathrm{E}$ to $270.0^{\circ} \mathrm{E}$ longitude. Here, we have selected about 5500 NAC images, in which we identified about $\sim 40,000$ independent stereo combinations which yield a connected block consisting of about 5200 MDIS NAC images. For the bundle block adjustment 75,000 tie point observation were used, which improves the 3D point accuracy from $\pm 890 \mathrm{~m}$ to $\pm 45 \mathrm{~m}$. From dense image matching we derived about 10.3 billion surface points with a mean accuracy of about $\pm 40 \mathrm{~m}$. The gridded DTM is centered at $225^{\circ} \mathrm{E}$ degree longitude (see figure 3 ). The vertical accuracy of the H12 DTM is about $35 \mathrm{~m}$. H12 DTM comprises a total height range of $8.9 \mathrm{~km}$. The model features two large basins (see Figure 3), the southern part of Beethoven basin $(\sim 650 \mathrm{~km}$ diameter $)$ and the eastern part of Dostojevskij basin $(\sim 430 \mathrm{~km}$ diameter)

\subsection{H13 Quadrangle "Neruda"}

The $\mathrm{H} 13$ quadrangle extends from $90.0^{\circ} \mathrm{E}$ to $180.0^{\circ} \mathrm{E}$ longitude. Here, we selected in total about 7000 NAC images, where we identified about $\sim 20,000$ independent stereo combinations which yield a connected block consisting of about 4600 images. For the bundle block adjustment 80,000 tie point observation were used, which improves the $3 \mathrm{D}$ point accuracy from $\pm 840 \mathrm{~m}$ to $\pm 45 \mathrm{~m}$. From dense image matching we derived about 4.2 billion surface points with a mean accuracy of about \pm 40 . The gridded DTM is centered at $135^{\circ} \mathrm{E}$ degree longitude (see Figure 4). The vertical accuracy of the H13 DTM is about $35 \mathrm{~m}$. H13 DTM comprises a total height range of $8.5 \mathrm{~km}$. The model highlights two large basins (see Figure 4), the eastern part of Rembrandt basin ( $740 \mathrm{~km}$ diameter) and also the western part of Dostojevskij basin ( $430 \mathrm{~km}$ diameter).

\subsection{H14 Quadrangle "Debussy"}

The $\mathrm{H} 14$ quadrangle extends from $0.0^{\circ} \mathrm{E}$ to $90.0^{\circ} \mathrm{E}$ longitude. We selected in total about 6500 NAC images. We identified about $\sim 30,000$ independent stereo combinations which yield a connected block consisting of about 5400 MDIS NAC images. For the bundle block adjustment 85,000 tie point observation were used, which improves the 3D point accuracy from $\pm 930 \mathrm{~m}$ to $\pm 50 \mathrm{~m}$. From dense image matching we derived about 10.6 billion surface points with a mean accuracy of about \pm 45 . The gridded DTM is centered at $45^{\circ} \mathrm{E}$ degree longitude (see Figure 5). The vertical accuracy of the H13 DTM is about $40 \mathrm{~m}$. The H14 DTM comprises a total height range of $8.5 \mathrm{~km}$. This model includes the western part of Rembrandt impact basin $(\sim 740 \mathrm{~km}$ diameter) and an unnamed basin ( $\sim 690 \mathrm{~km}$ diameter) westward to Debussy crater (Figure 5).

\section{SUMMARY AND OUTLOOK}

We are producing high-resolution topographic models for Mercury from stereo images obtained by the MESSENGER spacecraft during its orbital mission. While we presented models for the four southern quadrangles H11, H12, H13, and H14 in this paper, we aim at the production of a complete global terrain model for the planet. This will require the combined adjustment of the images for all quadrangles. This project also requires further discussions of the camera thermal model and the Mercury reference frame. The models provide important insights into the structure of large impact basins and Mercury's extended groove system.

\section{ACKNOWLEDGEMENTS}

The DTM data are currently prepared for release and will be available at PDS website (https://pdsimage2.wr.usgs.gov/ archive/mess-h-mdis-5-dem-elevation-v1.0/MESSDEM 1001/DEM/QUAD/IMG/). S.B. and J.O. were supported by a grant from the German Science Foundation (DFG), GZ: OB 124/11-1.

\section{REFERENCES}

Albertz, J., Wiggenhagen, M., 2009. Taschenbuch zur Photogrammetrie und Fernerkundung. Wichmann.

Denevi, B.W., Chabot, N.L., Murchie, S.L., Becker, K.J., Blewett, D.T., Domingue, D.L., Ernst, C.M., Hash, C.D., Hawkins, S.E., Keller, M.R., Laslo, N.R., Nair, H., Robinson, M.S., Seelos, F.P., Stephens, G.K., Turner, F.S., Solomon, S.C., 2017. Calibration, Projection, and Final Image Products of MESSENGER's Mercury Dual Imaging System. Space Sci Rev $214,2$.

Elgner, S., Stark, A., Oberst, J., Perry, M.E., Zuber, M.T., Robinson, M.S., Solomon, S.C., 2014. Mercury's global shape and topography from MESSENGER limb images. Planetary and Space Science 103, 299-308.

Greeley, R., Batson, R.M., 1990. Planetary mapping / edited by Ronald Greeley, Raymond M. Batson. Cambridge University Press, Cambridge, England.

Gwinner, K., Scholten, F., Spiegel, M., Schmidt, R., Giese, B., Oberst, J., Heipke, C., Jaumann, R., Neukum, G., 2009. Derivation and Validation of High-Resolution Digital Terrain Models from Mars Express HRSC Data.

Hawkins, I., S. Eduard, Boldt, J.D., Darlington, E.H., Espiritu, R., Gold, R.E., Gotwols, B., Grey, M.P., Hash, C.D., Hayes, J.R., Jaskulek, S.E., Kardian, C.J., Jr., Keller, M.R., Malaret, E.R., Murchie, S.L., Murphy, P.K., Peacock, K., Prockter, L.M., Reiter, R.A., Robinson, M.S., Schaefer, E.D., Shelton, R.G., Sterner, I., Raymond E., Taylor, H.W., Watters, T.R., Williams, B.D., 2007. The Mercury Dual Imaging System on the MESSENGER spacecraft. Space Sci Rev 131, 247-338.

Oberst, J., Preusker, F., Phillips, R.J., Watters, T.R., Head, J.W., Zuber, M.T., Solomon, S.C., 2010. The morphology of Mercury's Caloris basin as seen in MESSENGER stereo topographic models. Icarus 209, 230-238.

Perry, M.E., Neumann, G.A., Phillips, R.J., Barnouin, O.S., Ernst, C.M., Kahan, D.S., Solomon, S.C., Zuber, M.T., Smith, D.E., Hauck, I., S. A., Peale, S.J., Margot, J.L., Mazarico, E., Johnson, C.L., Gaskell, R.W., Roberts, J.H., McNutt, R.L., Oberst, J., 2015. The low-degree shape of Mercury. Geophysical Research Letters 42, 6951-6958.

Preusker, F., Oberst, J., Head, J.W., Watters, T.R., Robinson, M.S., Zuber, M.T., Solomon, S.C., 2011. Stereo topographic models of Mercury after three MESSENGER flybys. Planetary and Space Science 59, 1910-1917.

Preusker, F., Stark, A., Oberst, J., Matz, K.-D., Gwinner, K., Roatsch, T., Watters, T.R., 2017. Toward high-resolution global topography of Mercury from MESSENGER orbital stereo 
imaging: A prototype model for the H6 (Kuiper) quadrangle. Planetary and Space Science 142, 26-37.

Scholten, F., Gwinner, K., Roatsch, T., Matz, K.-D., Wählisch, M., Giese, B., Oberst, J., Jaumann, R., Neukum, G., HRSC CoI-Team, 2005. Mars Express HRSC Data Processing - Methods and Operational Aspects. Photogrammetric Engineering and Remote Sensing 71, 1143-1152.

Wewel, F., 1996. Determination of conjugate points of stereoscopic three line scanner data of Mars 96 mission. International Archives Photogrammetry and Remote Sensing 31,3 .

Zuber, M.T., Smith, D.E., Phillips, R.J., Solomon, S.C., Neumann, G.A., Hauck, I., S. A., Peale, S.J., Barnouin, O.S., Head, J.W., Johnson, C.L., Lemoine, F.G., Mazarico, E., Sun, X., Torrence, M.H., Freed, A.M., Klimczak, C., Margot, J.L., Oberst, J., Perry, M.E., McNutt, R.L., Balcerski, J.A., Michel, N., Talpe, M.J., Yang, D., 2012. Topography of the Northern Hemisphere of Mercury from MESSENGER Laser Altimetry. Science 336, 217-220.

Revised March 2018 